\title{
Processing of CNTs Reinforced Al-Based Nanocomposites Using Different Consolidation Techniques
}

\author{
N. Al-Aqeeli \\ Mechanical Engineering Department, King Fahd University of Petroleum \& Minerals (KFUPM), Dhahran 31261, Saudi Arabia \\ Correspondence should be addressed to N. Al-Aqeeli; naqeeli@kfupm.edu.sa
}

Received 5 August 2013; Revised 21 September 2013; Accepted 21 September 2013

Academic Editor: Fathallah Karimzadeh

Copyright (c) 2013 N. Al-Aqeeli. This is an open access article distributed under the Creative Commons Attribution License, which permits unrestricted use, distribution, and reproduction in any medium, provided the original work is properly cited.

\begin{abstract}
In this work, the development of two types of Al-based alloys with different concentrations of Si reinforced with MWCNT's at 0.5$2.0 \mathrm{wt} \%$ is presented. Sonication of the CNT's in ethyl alcohol was carried out for dispersion, and the mixtures were ball milled for 1,3 , and $5 \mathrm{hrs}$. SEM/EDS were used to study the morphology and the effects of changing milling parameters in addition to changes caused due to increasing concentration of the CNT's. Furthermore, three sintering techniques, namely, Spark Plasma Sintering (SPS), Microwave Sintering ( $\mu$ WS), and Hot Isostatic Press Sintering (HIP) were employed to consolidate the ball milled powders at varying temperatures of 400,450 , and $500^{\circ} \mathrm{C}$. It was found that SPS consolidated samples showed the most promising results amongst the three with the highest hardness values; around $100 \%$ densification, as well as the finest microstructure. On the other hand, microwave sintered samples showed the least appealing results, this could be attributed to the poor temperature distribution and the pressureless nature of the technique. A sintering temperature of $500^{\circ} \mathrm{C}$ was found to be the most suitable for these types of alloys.
\end{abstract}

\section{Introduction}

Powder metallurgy $(\mathrm{P} / \mathrm{M})$ technique for synthesizing metal matrix composites (MMC's) such as Al-based composites has been widely adopted due to the ability to homogeneously distribute the second phase reinforcements $[1,2]$. The mixing of powders and the reinforcing agents after which compacting and sintering is done are the main steps in such synthesis techniques. P/M synthesized MMC's have shown excellent mechanical properties when compared with those produced by alternative manufacturing processes and monolithic aluminum systems. High strength and light weight components from aluminum and its alloys are of interest in many industrial applications; aluminum composites are preferred for applications ranging from structural materials, and in aerospace, automotive and petrochemical industries [13]. This is primarily due to the enhanced material properties, such as wear-, creep-resistance and improved specific strength and specific modulus compared to pure metal matrix. The high strength, high durability, better formability, weldability, resistance to oxidation, and corrosion makes these composites resourceful. Al-Si-Mg alloys which are heattreatable and form precipitates such as, $\mathrm{Mg}_{2} \mathrm{Si}, \mathrm{Al}_{3} \mathrm{Mg}_{2}$ are the most suitable candidates to achieve the aforesaid properties [4-8]. In general, Al-Si alloy systems are adopted for the automotive industry, especially for cylinder blocks, cylinder heads, pistons, and in the fabrication of valve lifters [9, 10]. The incorporation of $\mathrm{Mg}$ into the binary $\mathrm{Al}-\mathrm{Si}$ alloys augments the properties of such alloy systems and these alloys are the so-called A356 Al-alloy series [3].

During the last two decades, the development of CNT's has opened new possibilities for their utilization due to their remarkable properties [11-13]. The augmentation of CNT's via $\mathrm{P} / \mathrm{M}$ technique has successfully enhanced the strength of Al-based alloys in multiple trials [14, 15]. Nevertheless, the possible agglomeration of CNT's results in poor dispersion into such a matrix leading to a weak matrix-CNT interface, yet, ball milling has been viewed to significantly disperse CNT's at optimized parameters such as milling time, sonication, and other milling conditions [2, 9, 14-20]. In an earlier study [21], the effect of the morphology and diameter of CNT's in processing $\mathrm{Al} / \mathrm{CNT}$ composites was considered. It 
was shown that the smaller the diameter and the more bent and entangled the CNT's the more difficult they become to disperse as compared to larger straighter and stiffer CNT's.

As a result of using $\mathrm{P} / \mathrm{M}$ processing route, the synthesized mixtures are always in the powder form; this makes it necessary to use consolidation techniques to produce near-netshape components. During the sintering and densification, the average size increases as a result of the thermal energy applied to the powder compact. In general, sinterability and the sintered microstructure of a powder compact are dependent on material and process variables and the sintering equations that are governed by these important variables [22]. In addition to impurity content and composition, the sintering atmosphere also impacts the sintering mechanism. The major changes caused by sintering atmosphere are high gas transportation rates and changes in pore structure, grain structure, impurity content, kinetics, and surface structures. Therefore, specifications of the atmosphere are most relevant for better control of impurity.

Consolidation of powders through isostatic technique is feasible for composite materials which are intricate or costly to fabricate by other methods [23]. In general, conventional sintering techniques (CIP or HIP) are performed at room or higher temperatures while using liquid and gas as the medium of pressure transmission, in CIP and HIP respectively [24]. In CIP, the powder is converted from a loose aggregate into a partially-dense compact that has enough green strength to permit cautious handling and transfer to the following process operation. On the other hand, HIP is required when full or considerable consolidation of composite powders is needed and CIP may be involved in most cases at a preliminary processing stage, since HIP commences with pressurization of the HIP unit while it is still comparatively cold. Conventional techniques have the advantages of processing immiscible systems, high melting point materials, and the properties of the compacted components are isotropic especially for randomly mixed powders [23]. Nevertheless, HIP is characterized as a low-heat sintering technique [25]. In multiple literature sources [14, 26-28], conventional sintering techniques were used to consolidate $\mathrm{Al} / \mathrm{CNT}$ matrix and all the studies reported significant increase in tensile strength and stiffness as well as good dispersion of the CNT's after ball milling.

Nonconventional sintering techniques, such as Microwave and Spark plasma, are novel techniques differentiated from conventional ones by the heating mechanism. In conventional sintering, heat is generated and transferred to the material through conduction, convection, and radiation, while in microwave sintering the materials themselves absorb microwave energy and then transform it into heat within their bodies [29]. The microwave technique involves radiant/resistance heating followed by transfer of thermal energy through the conduction to the inside of the body under processing via thermal conductivity mechanisms [29], while SPS employs an electrical discharge combined with resistance heating and pressure for sintering. Both techniques have superior advantages over the conventional ones. For example, very rapid heating and cooling rates, shortened sintering times, improved microstructure, higher densification, in addition to enhanced mechanical properties. These nonconventional methods have made it possible for the processing of advanced materials and the avoidance of undesirable grain growth in the synthesis of nanomaterials. These techniques were used elsewhere [30-32] to investigate the effects of nonconventional sintering techniques on Al-CNT system and reported an increase in hardness and stiffness as well as improvement in microstructure.

In this present work, prealloyed Al-7Si-0.3Mg and Al$12 \mathrm{Si}-0.3 \mathrm{Mg}$ with MWCNT's as reinforcements ranging from 0.5-2.0 wt $\%$ were synthesized using solid-state synthesis. FESEM and optical imaging were used to characterize the milled and the consolidated products. Hot isostatic pressing, Microwave, and spark plasma sintering techniques were employed and comparative analyses were made in terms of the microstructure, densification, and microhardness of the sintered samples.

\section{Experimental Procedure}

2.1. Materials. Prealloyed Al-7Si-0.3Mg and Al-12Si-0.3Mg powders (procured from Aluminum Powder Co. Ltd. England) were used as alloys' matrices, and Table 1 shows the chemical analyses of the alloys with average particle sizes of $40 \mu \mathrm{m}$. MWCNT's (Diameter: 20-40 nm, length: 5-15 $\mu \mathrm{m}$, purity: more than $95 \%$, surface density: $40-600 \mathrm{~m}^{2} / \mathrm{g}$ ) provided by Nanostructured and Amorphous materials Inc. (Houston, Texas, USA) were used as a reinforcement with a concentration between $0.5-2.0 \mathrm{wt} \%$.

2.2. Ball Milling of Powder. Al-based powders were ball milled with CNT's to produce a homogeneous mixture after sonication with ethyl alcohol for 10-15 minutes. For the milling experiments, the powders were loaded in a stainless steel vial and milled in a Planetary mill (Fritsch Pulverisette 5) under Argon (Ar) atmosphere to reduce/eliminate contamination. Stearic acid (2\% wt) was used as a process control agent (PCA) to avoid excessive cold welding of aluminum powders. Stainless steel balls were used, each ball weighed $4.1 \mathrm{~g}$ and the ball-to-powder weight ratio (BPR) was set at $10: 1$. Milling was carried out at a speed of $200 \mathrm{rpm}$ for different milling periods of 1,3 , and 5 hours. For longer experiments, milling was periodically halted after an interval of $1.5 \mathrm{hrs}$ for 30 minutes to avoid temperature build-up in the milling vial. Furthermore, to eliminate any accumulation of unprocessed powders on the internal walls, the vial was opened at regular intervals depending on the milling time and the deposited powders were scraped out from the vial walls.

2.3. Powder Characterization. At successive milling times, a small amount of powder (around 1 gram) was taken out from the vials to observe morphological changes. JEOL JSM6460LV scanning electron microscope (SEM) was used for morphological evaluations. In addition, Optical microscope (MEIJI-Techno microscope, Japan) was used for further characterizations. Oxford system for EDS (Energy-dispersive $\mathrm{X}$-ray spectroscopy) along with mapping was utilized for the compositional analysis. 


\subsection{Sintering Techniques}

2.4.1. Spark Plasma Sintering. Ball milled powders were sintered using SPS FCT group, SystemeGmBH, (Germany) at 400,450 , and $500^{\circ} \mathrm{C}$ with a holding time of 20 minutes using a force of $11 \mathrm{KN}(35 \mathrm{MPa})$ at a heating rate of $100^{\circ} \mathrm{C} / \mathrm{min}$ with a die movement between 6 and $7.5 \mathrm{~mm}$.

2.4.2. Powder Compaction. A $7 \mathrm{~g}$ sample of ball milled powder was compacted to produce a green compact of $20 \mathrm{~mm}$ diameter and $10 \mathrm{~mm}$ height using uniaxial pressing machine (Auto-Series manufactured by Carver, Indiana, USA) at a load of $14,500 \mathrm{lb}$ with a dwell time of 5 minutes and cold pressed at 44,000 Psi for 5 minutes. These compacts were made for both microwave and Hot Isostatic Pressing.

2.4.3. Microwave Sintering. Microwave sintering was performed using Puscher Microwave Power System, $\mu$ wave Vac08-Sin, (Germany) while holding for 20 minutes at 400, 450 , and $500^{\circ} \mathrm{C}$ sintering temperatures.

2.4.4. Hot Isostatic Pressing (HIP) Sintering. HIP sintering was accomplished using American Isostatic Press Inc; hold press HP 630, (USA), while holding for 30 mins. Sintering temperatures were also varied at 400,450 , and $500^{\circ} \mathrm{C}$.

2.5. Mechanical Characterization. Microhardness was measured using Vickers hardness machine (MMT-3 digital microhardness tester, Buehler, USA) using 100 gf taking 1012 readings on each sample. Density measurements of the sintered as-received monolithic alloys and CNT reinforced $\mathrm{Al}$-alloys were performed using an electronic densimeter (MD-300S, Alfa Mirage, SG resolution- $0.001 \mathrm{~g} / \mathrm{cm}^{3}$, capacity$300 \mathrm{~g}$ ) based on Archimedes principle.

\section{Results and Discussion}

3.1. SEM Micrographs of As-Received and Milled Powders. Mixture of prealloyed Al-Si-Mg alloys with CNT's (both alloy 1 and 2 according to Table 1 containing $0.5-2.0 \mathrm{wt} \%$ CNT's) composite powders were synthesized by ball milling for 1 , 3 , and $5 \mathrm{~h}$. Figure 1 presents SEM micrographs, showing the effect on the morphology of $\mathrm{Al}$ powder for samples milled at 1,3 , and $5 \mathrm{~h}$, respectively.

Figures 1(a) and 1(e) shows the morphology of the asreceived aluminum powders (alloy 1 and 2, resp.) and it can be observed that the as-received powder particles were primarily spherical in shape with variable particle sizes. According to the chemical analyses of the starting as-received powders there is a minute change in the composition from the prescribed one. Figures 1(b) and 1(f) shows the powder mixture containing $0.5 \mathrm{wt} \%$ CNT's milled for $1 \mathrm{~h}$ for alloys 1 and 2 respectively; where the segregation of CNT's was observed with partial agglomeration and clusters. This occurred despite the fact that sonication was performed on the CNT's before augmenting them into the milling process. In Figures 1(c) and $1(\mathrm{~g})$ morphology appears different when compared with asreceived powder and shows fractional transformation from spherical to more flattened particles because $3 \mathrm{~h}$ of ball milling progressively forms flake-like particles; it is also observed that CNT's more or less start to disappear. At the final stage of ball milling, the surface of the powder particles appears more flake-like. However, after $5 \mathrm{~h}$ of milling CNT's were observed on the surface of the flake-like particles in sporadic locations (Figures $1(\mathrm{~d})$ and $1(\mathrm{~h})$ ). It can be suggested at this stage that the embedded CNT's in between the welded particles during $3 \mathrm{~h}$ of ball milling appeared on the more flattened surface; where SEM analysis revealed the presence of CNT's within the aluminum matrix (as confirmed by EDS). It can be seen that the CNT's appear somewhat intact after being subjected to the milling process. CNT clustering was observed after $1 \mathrm{~h}$ of milling, as shown in Figures $1(\mathrm{~b})$ and 1(f). Whereas this disappeared after $3 \mathrm{~h}$ when the CNT's became dispersed in the cold welded surfaces of the particles. With the rewelding of the aluminum particles after $3 \mathrm{~h}$ under the impact of the balls, individual CNT's were observed on the surface of aluminum particles (Figures $1(\mathrm{~d})$ and $1(\mathrm{~h})$ ). This may be evidence for the embodiment of CNT's in the aluminum matrix.

Figure 2 shows SEM micrographs for both alloys containing $2.0 \mathrm{wt} \%$ CNT milled for 1,3 , and $5 \mathrm{~h}$ of ball milling, again similar trends were observed as those seen in Figure 1 above. In comparison, Figure 2 shows more CNT agglomerations which is attributed to increased CNT content; this is evident from Figures 2(a) and 2(b)) showing the morphology as well as wide spread CNT agglomeration. In general, it seems that short milling times result in agglomeration of CNT's whereas long milling times disperse the CNT's into the aluminum matrix in a more preferred fashion, at the expense of cold welding of aluminum. However, during short milling, the addition of higher contents of CNT can have an adverse effect on the densification and homogeneity of the resulting alloys. It was reported elsewhere [33] that the porosity level is increased with increasing the CNT content since more CNT's can lead to forming agglomerates which cause less uniform and homogeneous alloys. Therefore, the results presented later in this work will be limited to CNT content of $0.5 \mathrm{wt} \%$ as it shows promising results in terms of homogeneity and distribution of CNT's into the alloy matrix.

\subsection{Sintered Sample Characterization}

3.2.1. Densification and Hardness of Sintered Samples. Figures 3, 4, 5, and 6 represent (a) densification and (b) vickers hardness values from as-received monolithic Al-7Si$0.3 \mathrm{Mg}, \mathrm{Al}-12 \mathrm{Si}-0.3 \mathrm{Mg}$ and for the same alloys containing 0.5 wt $\%$ CNT's. All alloys were sintered at variable temperatures of 400,450 , and $500^{\circ} \mathrm{C}$ in addition to the different sintering techniques to depict the best sintering conditions for the highest values of densification and hardness. In general, all sintering techniques showed an increase in hardness as the sintering temperature was increased from 400 to $500^{\circ} \mathrm{C}$. The incorporation of $0.5 \mathrm{wt} \% \mathrm{CNT}$ in both alloys showed better hardness values as compared to their respective as-received monolithic alloys. It appears that as a general trend, SPS samples had the highest densification and hardness values which are due to the low porosity 
TABLE 1: Chemical analysis of starting powder of Al-7Si-0.3Mg alloy (alloy-1) and Al-12Si-0.3Mg alloy (alloy-2).

\begin{tabular}{lcccccccccccccc}
\hline Composition & $\mathrm{Al}$ & $\mathrm{Si}$ & $\mathrm{Mg}$ & $\mathrm{Fe}$ & $\mathrm{Mn}$ & $\mathrm{Cu}$ & $\mathrm{Zn}$ & $\mathrm{Pb}$ & $\mathrm{Co}$ & $\mathrm{Ni}$ & $\mathrm{Cr}$ & $\mathrm{Ti}$ & $\mathrm{Zr}$ & $\mathrm{Ga}$ \\
\hline Alloy 1 & 92.06 & 6.5 & 0.40 & 0.35 & 0.040 & 0.037 & 0.015 & 0.015 & 0.001 & 0.011 & 0.004 & 0.016 & 0.001 & 0.010 \\
Alloy 2 & 87.49 & 11.2 & 0.41 & 0.64 & 0.067 & 0.067 & 0.023 & 0.046 & 0.001 & 0.014 & 0.005 & 0.023 & 0.002 & 0.012 \\
\hline
\end{tabular}
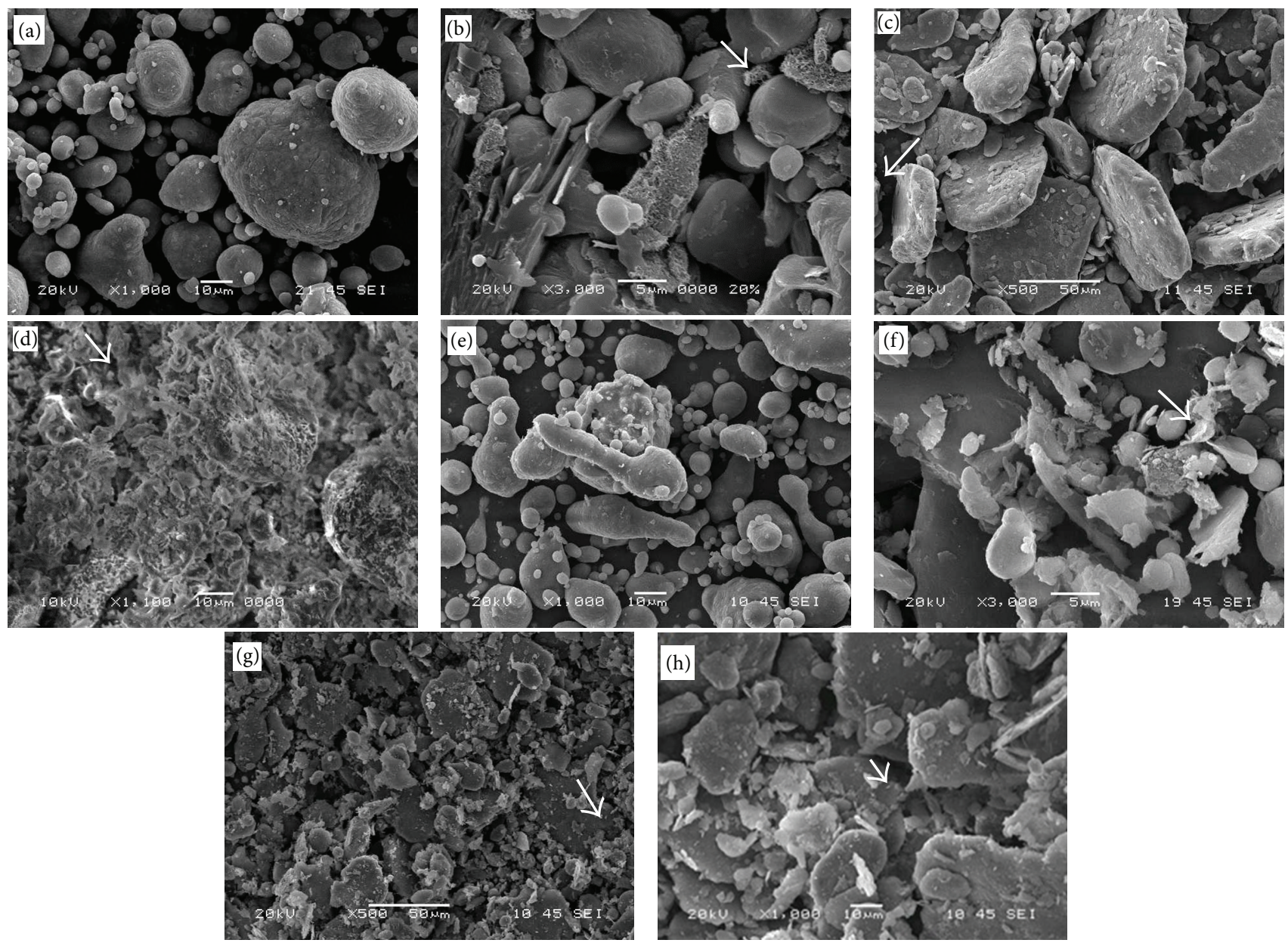

FIGURE 1: SEM micrographs of alloys 1 and 2; (a) as received alloy-1 (Al-7Si-0.3Mg), ((b), (c), (d)) alloy-1 containing 0.5 wt\% CNT's and milled for 1,3 , and $5 \mathrm{~h}$, respectively and micrograph (e) as received alloy-2 (Al-12Si- $0.3 \mathrm{Mg}$ ) and ((f), (g), (h)) alloy-2 containing $0.5 \mathrm{wt} \%$ CNT's and milled for 1,3 , and $5 \mathrm{~h}$, respectively. Arrows show the presence of CNTs.

level as compared with microwave and HIP samples. Other reasons for the high densification values in the SPS samples can be attributed to the high heating and cooling rates, uniaxial pressure coupled with the spark discharge during the sintering which in turn leads to minimal grain growth as compared to other sintering techniques. Microwave sintered samples recorded the lowest values of hardness and densification due to the high porosity level which affected the properties significantly. Heat distribution in the microwave sintering technique also contributed to the low values. These results show that SPS is most suitable for sintering of these alloys irrespective of the addition of CNT's. Despite the fact that there is a recorded improvement due to increasing the content of CNT's in the processed alloys, the behavior, however, was very similar to the one observed in $0.5 \mathrm{wt} \%$ CNT's.
The increase in densification was quite high when the temperature was increased from 400 to $450^{\circ} \mathrm{C}$ and then slowed down as we moved from 450 to $500^{\circ} \mathrm{C}$. This might suggest that $450^{\circ} \mathrm{C}$ might be the ideal temperature to obtain fully dense alloys with the use of HIP and SPS. However, the improvement in hardness was more pronounced when the sintering temperature was raised from 450 to $500^{\circ} \mathrm{C}$, which suggests the need to reach $500^{\circ} \mathrm{C}$ in order to attain better mechanical properties. Moreover, there is a pronounced difference in the densification values between microwave and the other techniques, which is in the range of $10 \%$; this is quite significant for certain applications. As for the hardness values, it seems that the addition of $0.5 \%$ wt CNT's had a small effect on improving the hardness of the resulting alloys. At higher concentrations of CNT's, the formation of carbides can result in appreciable enhancement in mechanical properties [21] but 

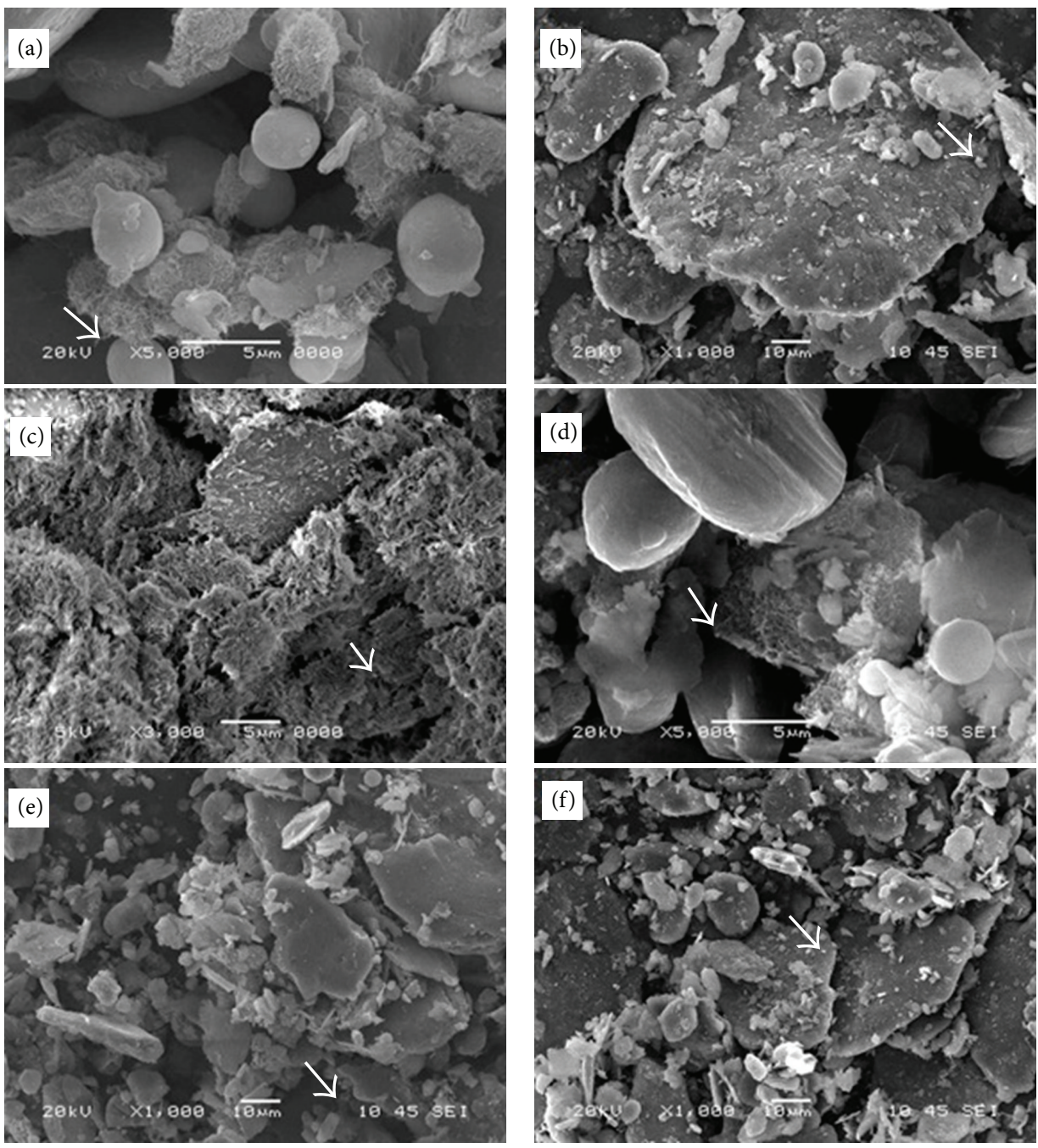

FIGURE 2: SEM micrographs of alloys 1 and 2; ((a), (b), (c)) alloy-1 containing $2.0 \mathrm{wt} \%$ CNT's and milled for 1, 3 and $5 \mathrm{~h}$ respectively and micrographs ((d), (e), (f)) alloy-2 containing $2.0 \mathrm{wt} \%$ CNT's and milled for 1,3 and $5 \mathrm{~h}$, respectively. Arrows show the presence of CNTs.

at the expense of densification and homogeneity of the resulting alloys. In some situations, there might be a formation of intermetallic phases that contribute in improving hardness values, yet, according to the results obtained herein it appears that the short milling time was not sufficient to introduce such phases. This might be supported by the minute increase in hardness values which does not support any hypothesis related to the formation of second phases that result from milling experiments and cannot be detected using XRD due to detectability limits.

3.2.2. SEM Micrographs of Sintered Samples. The use of $500^{\circ} \mathrm{C}$ as sintering temperature seems to give better results in terms of density and hardness measurements and therefore the upcoming analysis will be focused on revealing the morphology of these high performing alloys. Figures 7, 8, 9, and 10 are FESEM micrographs taken from as-received monolithic alloys 1 and 2 in addition to micrographs taken from the same alloys with the $0.5 \mathrm{wt} \%$ concentration of CNT's. In all figures, the alloys were sintered using (a) Microwave ( $\mu \mathrm{w}$ ) (b) Hot Isostatic Press (HIP), and (c) Spark Plasma (SPS) at a temperature of $500^{\circ} \mathrm{C}$. As shown in the micrographs, more pronounced porosity was observed in the microwave samples as compared to the HIP and SPS samples owing to the temperature distribution and pressureless nature of the technique. The dark grey regions are partially sintered while the light grey regions are fully sintered. In all cases, it appears that the SPS technique produces the maximum densification and the lowest porosity. Moving from microwave to HIP and then to SPS micrographs, it is evident that the porosity level decreases at the same sintering temperature, a finding that conforms with the densification data that was presented earlier.

It was also observed that the higher the temperature the higher the density of the resulting alloys; this observation is in agreement with results published for other $\mathrm{Al}$ alloy systems [34]. The use of higher temperatures helps reduce pores and improves the coalescence of particles which leads to higher 


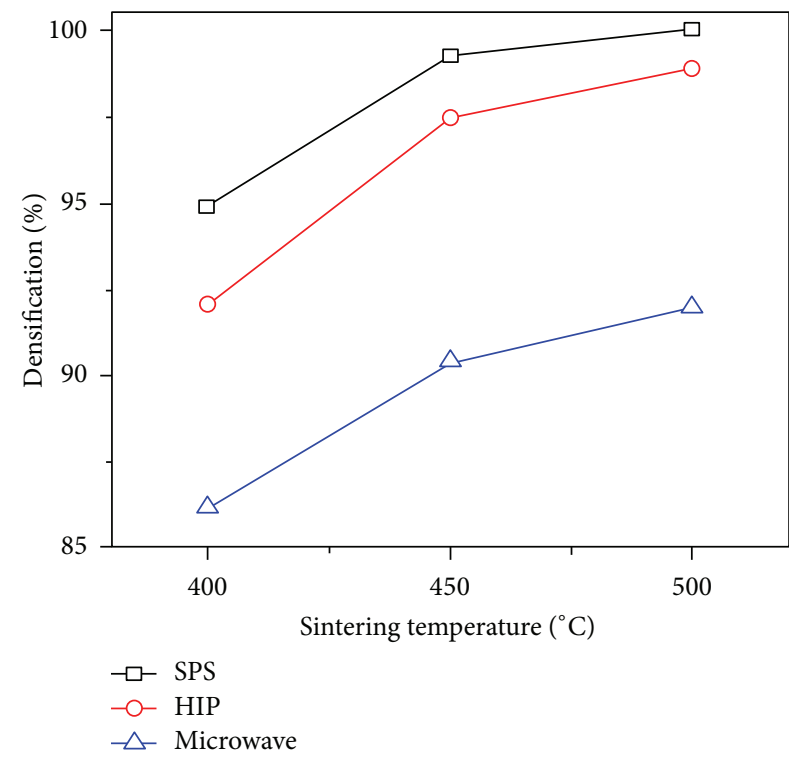

(a)

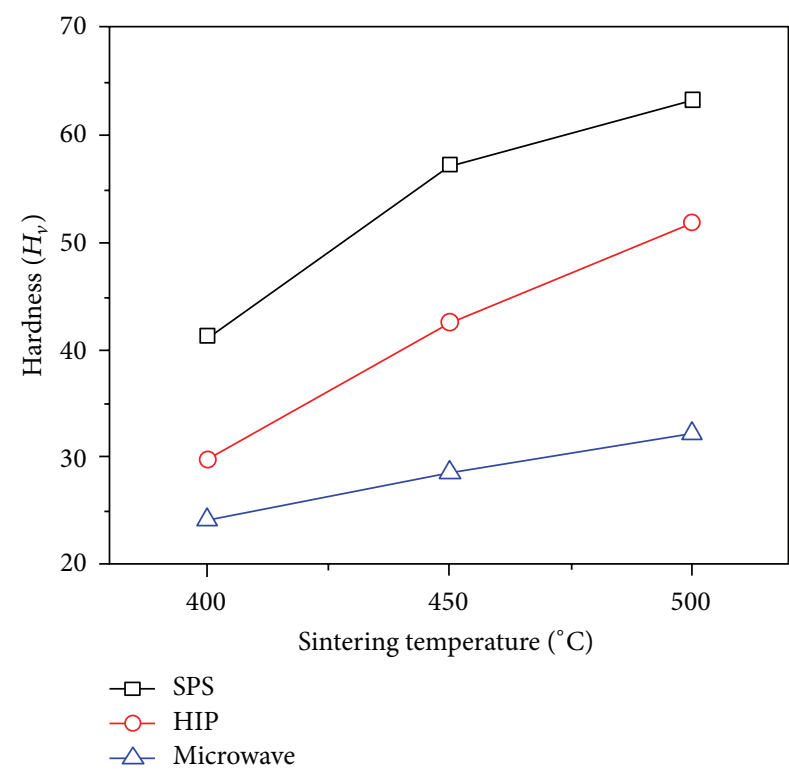

(b)

FIgURE 3: Shows densification (a) and hardness (b) of as-received Al-7Si- $0.3 \mathrm{Mg}$ alloy sintered at 400, 450, and $500^{\circ} \mathrm{C}$ using microwave, $\mathrm{HIP}$, and SPS techniques.

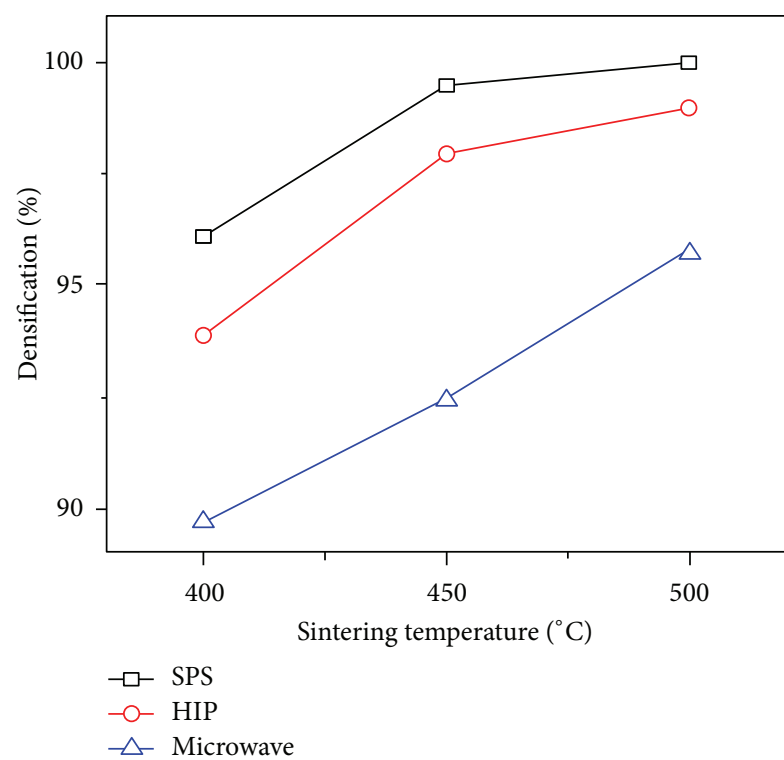

(a)

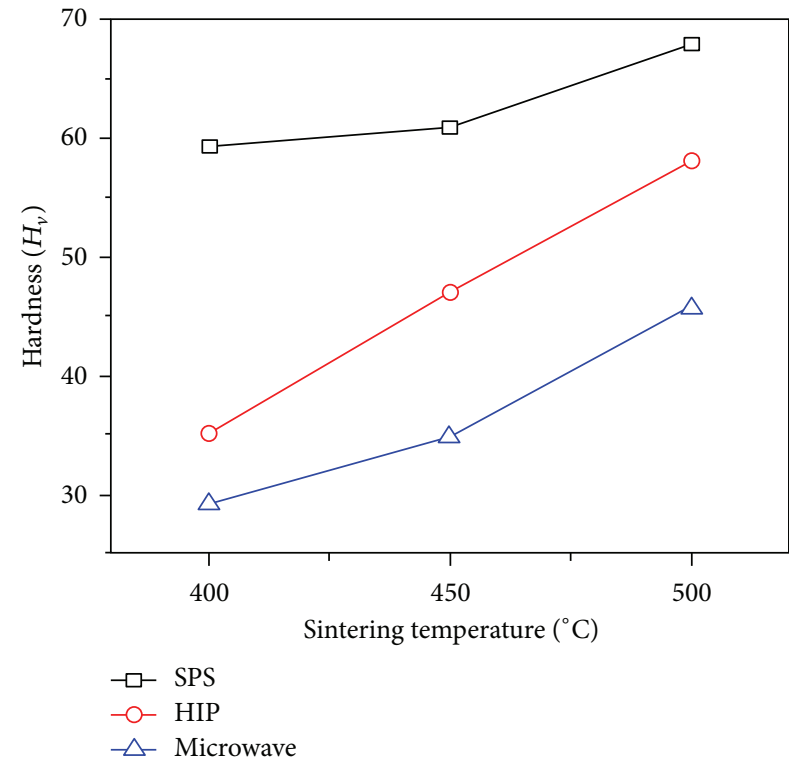

(b)

Figure 4: Shows densification (a) and hardness (b) of Al-7Si-0.3Mg $+0.5 \mathrm{wt} \% \mathrm{CNT}$ powder milled for $5 \mathrm{~h}$ and sintered at 400,450 , and $500^{\circ} \mathrm{C}$ using microwave, HIP, and SPS techniques.

density values. It is known that the sintering temperature has major effect on the resulting densification due to the nature of sintering, which is a thermally activated process that is controlled primarily by diffusion.

It can also be seen from the previous figures that the increased concentration of $\mathrm{Si}$ did not have a pronounced effect on the consolidation behavior of the $\mathrm{Al}$ nanocomposites. This corresponds with similar trends that can be seen from the previous SEM micrographs. Another interesting observation is the effect of milling on the alloys with CNT's before proceeding to consolidation. The above figures show that a small addition of CNT's to the Al alloys improved the densification behavior of Microwave consolidated sample. This is in agreement with the densification data that was presented; it is valid for both Alloy 1 and 2. This might be due to the improved surface coalescence between particles and 


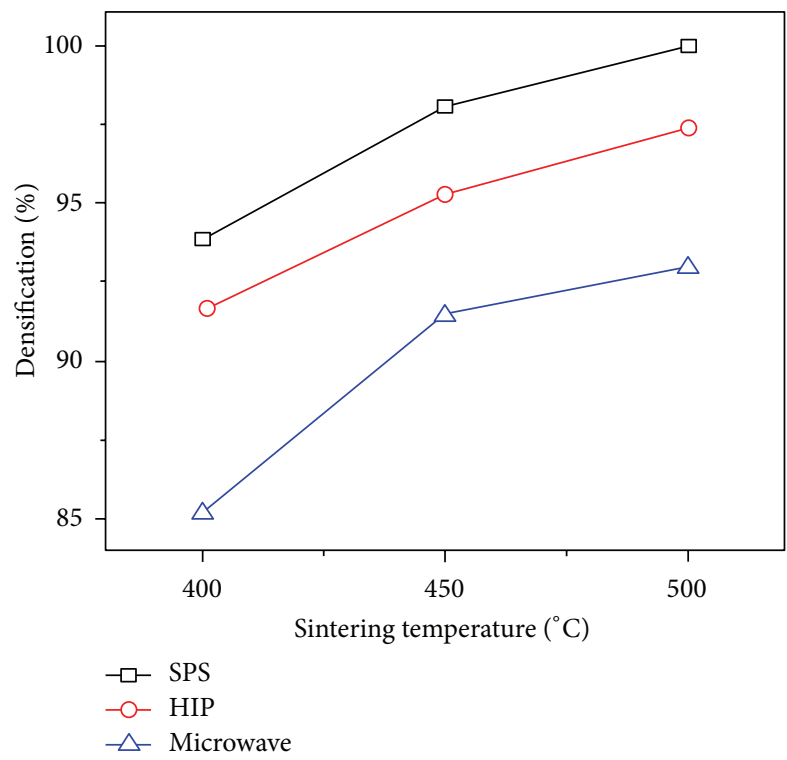

(a)

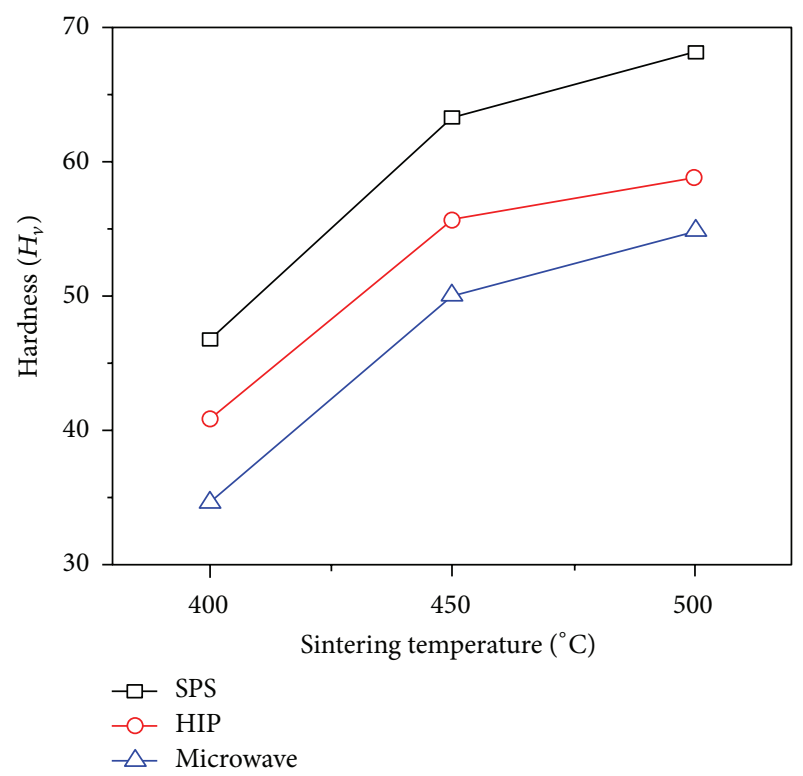

(b)

Figure 5: Shows densification (a) and hardness (b) of as-received Al-12Si-0.3Mg alloy sintered at 400, 450, and $500^{\circ} \mathrm{C}$ using microwave, $\mathrm{HIP}$, and SPS techniques.

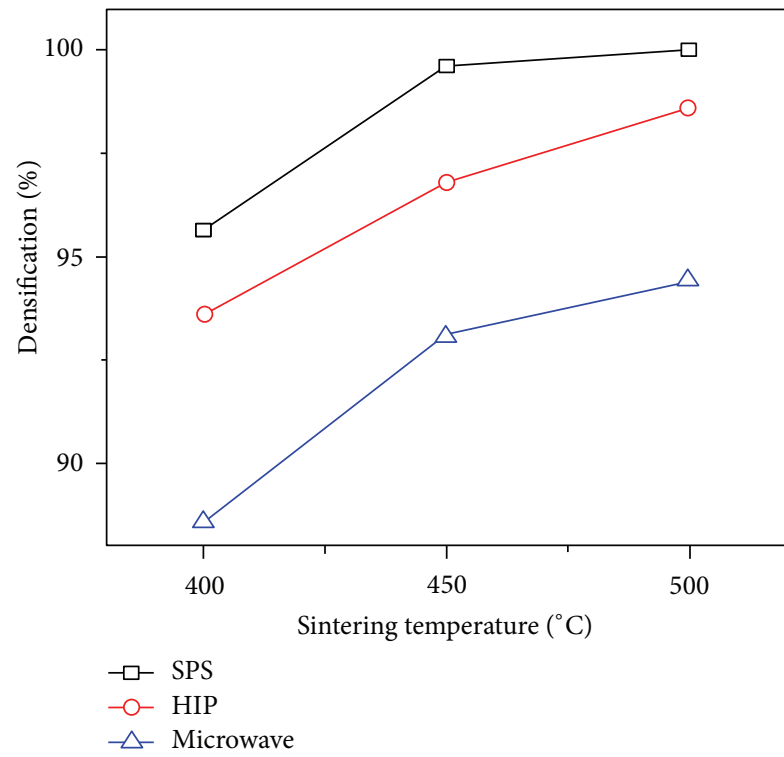

(a)

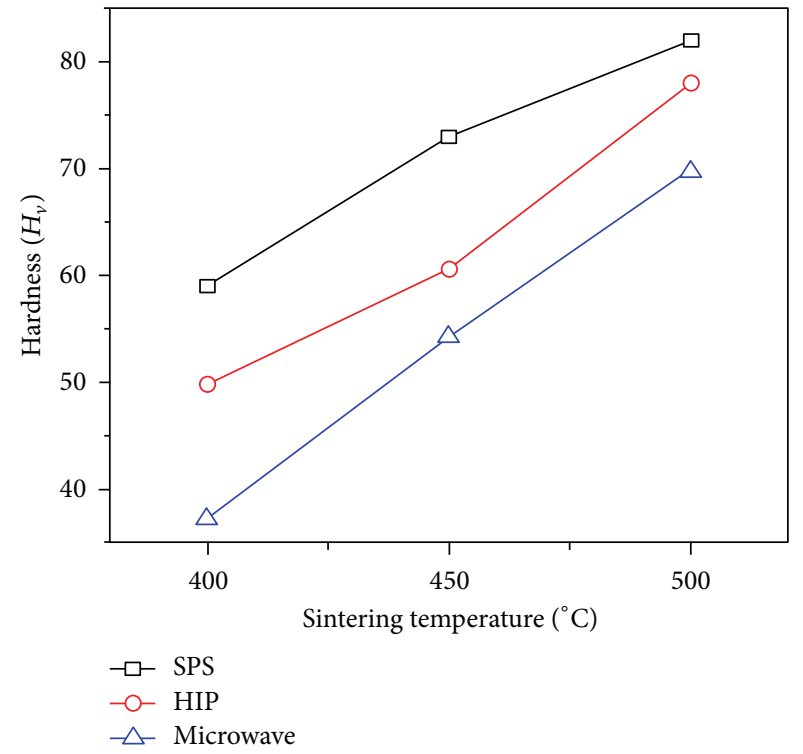

(b)

Figure 6: Shows densification (a) and hardness (b) of Al-12Si-0.3Mg $+0.5 \mathrm{wt} \%$ CNT powder milled for $5 \mathrm{~h}$ and sintered at 400 , 450 , and $500^{\circ} \mathrm{C}$ using microwave, HIP, and SPS techniques.

the possible enhancement of CNT augmentation. However, this might not be helpful at higher CNT content, where the possibility of CNT agglomeration can retard beneficial sintering. However, for the HIP and SPS sintered samples, there is not much improvement in densification according to the micrographs; which is again in agreement with the density measurement data. Despite the fact that SEM micrographs showed degradation in density in Alloy 2 when CNT's were added (Figures 7(b) and 8(b)) the densification data proved that the density values were increasing rather than decreasing.

It can be stated here that the observed differences in results were primarily due to the different mechanisms involved with the use of different sintering techniques. The rate of increase in temperature during sintering is lower in the microwave technique, which results in lower mass transport. 

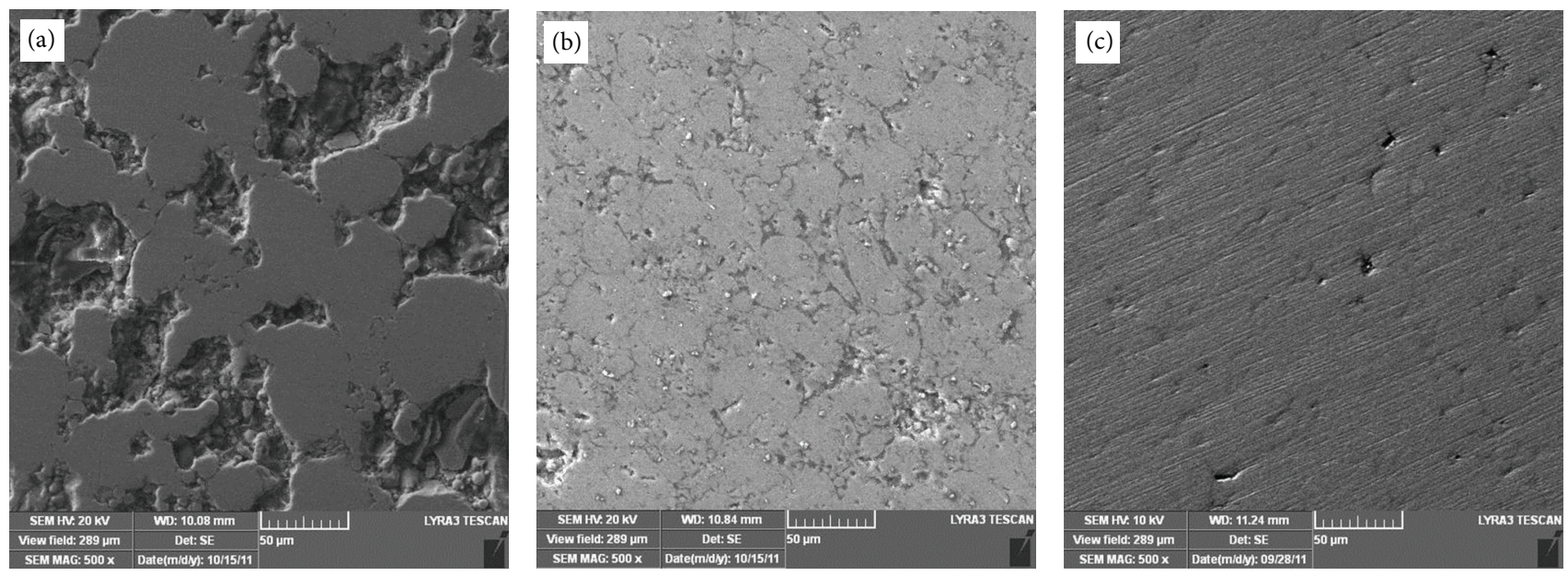

FIGURE 7: SEM micrographs of as-received Al-7Si-0.3Mg (alloy 1) sintered at $500^{\circ} \mathrm{C}$ using (a) microwave ( $\mu \mathrm{W}$ ), (b) hot isostatic pressing (HIP), and (c) Spark plasma (SPS).
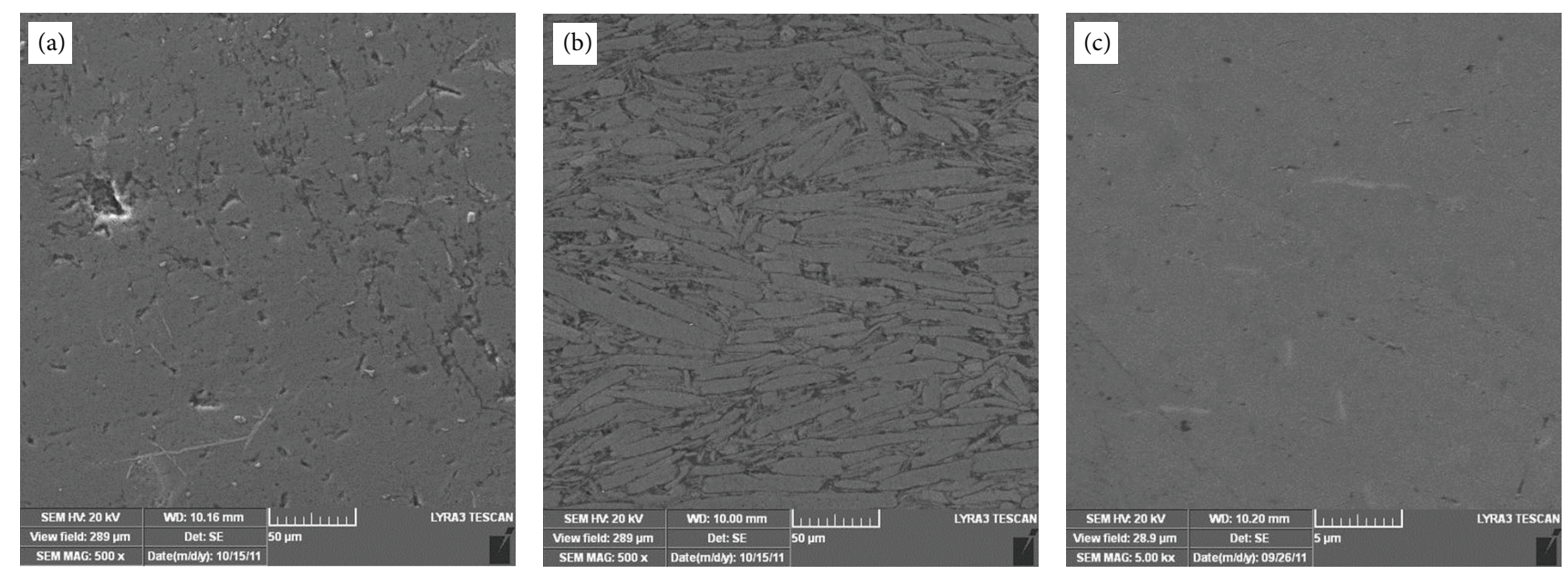

FIGURE 8: SEM micrographs of Al-7Si-0.3Mg (alloy 1) samples containing $0.5 \mathrm{wt} \% \mathrm{MWCNT}$ 's and sintered at $500^{\circ} \mathrm{C}$ using (a) microwave, (b) hot isostatic pressing (HIP), and (c) Spark plasma (SPS) sintered.
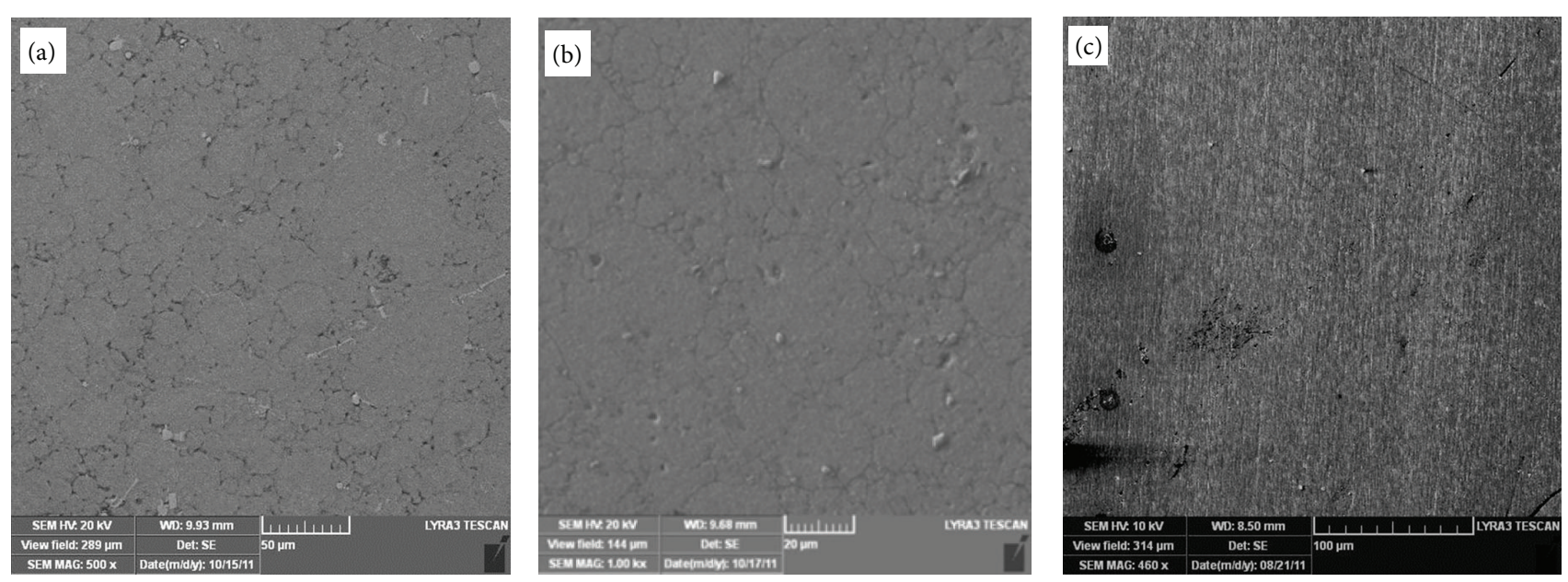

FIGURE 9: SEM micrographs of as-received Al-12Si-0.3Mg (alloy 2) and sintered at $500^{\circ} \mathrm{C}$ using (a) microwave, (b) hot isostatic pressing (HIP), and (c) Spark plasma (SPS) sintered samples. 

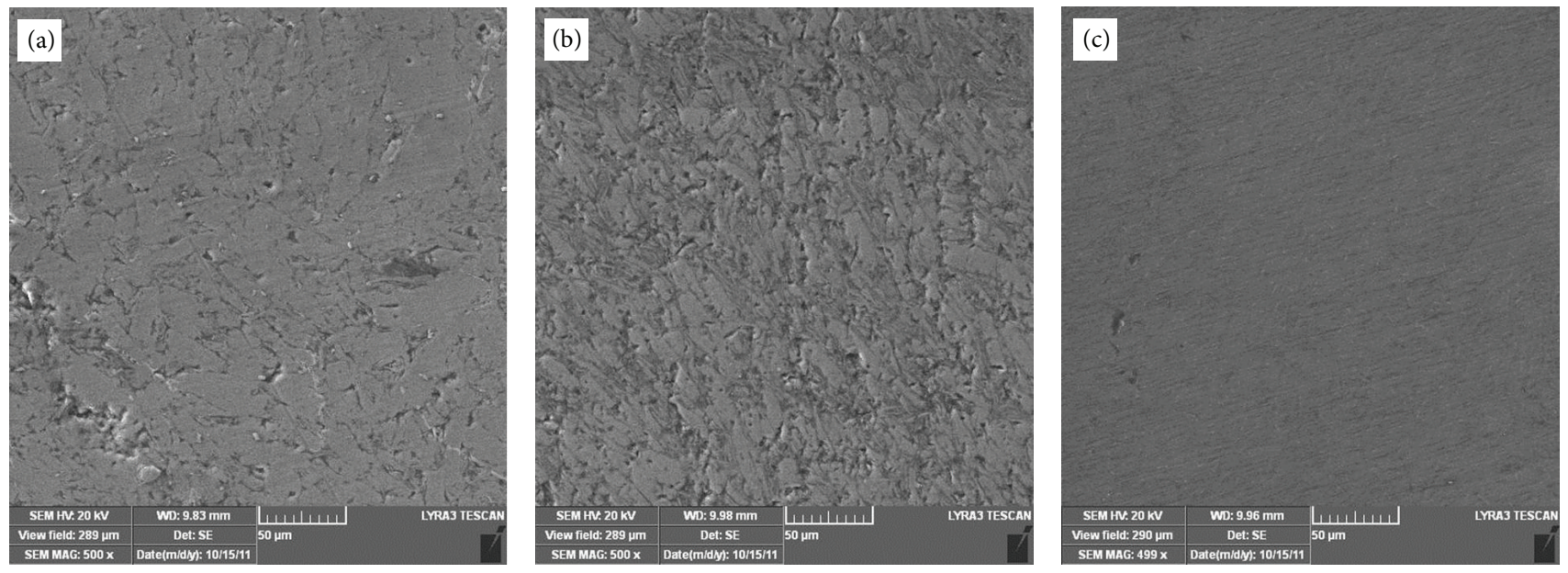

Figure 10: SEM micrographs of Al-12Si-0.3Mg (alloy 2) containing 0.5 wt\% MWCNT's and sintered at $500^{\circ} \mathrm{C}$ using (a) microwave, (b) hot isostatic pressing (HIP), (c) Spark plasma (SPS).

However, care should be taken while considering higher sintering temperatures, which might cause grain growth and result in lower hardness values.

\section{Conclusions}

In this work, a comparative study was conducted to reveal the effect of using different nonconventional sintering techniques. It was observed that mechanical alloying proved to be a successful method in finely dispersing the CNT's into the Al-based alloy matrix even with milling times as low as $5 \mathrm{~h}$. Amongst all sintering techniques used in this work, SPS proved to be the most suitable in yielding the highest hardness and densification values which were attributed to the low porosity level as compared with microwave and HIP. Moreover, it was shown that the higher the sintering temperature the better the densification and mechanical properties. The most desirable properties were obtained at a sintering temperature of $500^{\circ} \mathrm{C}$; however, it was noted that an increase in temperature could have adverse effects on the resulting properties due to undesirable grain growth. HIP has also shown promising results that were closer to those obtained by SPS, which were relatively higher than results obtained using the microwave technique. This is despite the fact that HIP was considered a low-heat sintering technique. To conclude, the difference in results could be attributed to the different heating mechanisms involved in the implementation of different techniques.

\section{Conflict of Interests}

The author declares that there is no conflict of interests regarding the publication of this paper.

\section{Acknowledgment}

The author wishes to express gratitude to the financial support provided by King Fahd University of Petroleum and
Minerals (KFUPM) to carry out this work through Grant no. IN111014.

\section{References}

[1] J. M. Torralba, C. E. da Costa, and F. Velasco, "P/M aluminum matrix composites: an overview," Journal of Materials Processing Technology, vol. 133, no. 1-2, pp. 203-206, 2003.

[2] J. B. Fogagnolo, F. Velasco, M. H. Robert, and J. M. Torralba, "Effect of mechanical alloying on the morphology, microstructure and properties of aluminium matrix composite powders," Materials Science and Engineering A, vol. 342, no. 1-2, pp. 131143, 2003.

[3] T. Moons, P. Ratchev, P. de Smet, B. Verlinden, and P. Van Houtte, "A comparative study of two Al-Mg-Si alloys for automotive applications," Scripta Materialia, vol. 35, no. 8, pp. 939945, 1996.

[4] X.-S. Jiang, G.-Q. He, B. Liu, S.-J. Fan, and M.-H. Zhu, "Microstructure-based analysis of fatigue behaviour of Al-SiMg alloy," Transactions of Nonferrous Metals Society of China, vol. 21, no. 3, pp. 443-448, 2011.

[5] K. Fukui, M. Takeda, and T. Endo, "Morphology and thermal stability of metastable precipitates formed in an Al-Mg-Si ternary alloy aged at $403 \mathrm{~K}$ to $483 \mathrm{~K}$," Materials Letters, vol. 59, no. 11, pp. 1444-1448, 2005.

[6] K. Matsuda, S. Ikeno, T. Sato, and Y. Uetani, "New quaternary grain boundary precipitate in Al-Mg-Si alloy containing silver," Scripta Materialia, vol. 55, no. 2, pp. 127-129, 2006.

[7] K. E. Knipling, R. A. Karnesky, C. P. Lee, D. C. Dunand, and D. N. Seidman, "Precipitation evolution in Al-0.1Sc, Al-0.1Zr and $\mathrm{Al}-0.1 \mathrm{Sc}-0.1 \mathrm{Zr}$ (at.\%) alloys during isochronal aging," Acta Materialia, vol. 58, no. 15, pp. 5184-5195, 2010.

[8] K. Banizs, "Dislocation structures caused by plastic deformations in an aged AlMgSi alloy," Materials Science and Engineering, vol. 41, no. 1, pp. 17-24, 1979.

[9] L. Wang, H. Choi, J.-M. Myoung, and W. Lee, "Mechanical alloying of multi-walled carbon nanotubes and aluminium powders for the preparation of carbon/metal composites," Carbon, vol. 47, no. 15, pp. 3427-3433, 2009. 
[10] S. R. Bakshi and A. Agarwal, "An analysis of the factors affecting strengthening in carbon nanotube reinforced aluminum composites," Carbon, vol. 49, no. 2, pp. 533-544, 2011.

[11] S. Iijima, "Helical microtubules of graphitic carbon," Nature, vol. 354, no. 6348, pp. 56-58, 1991.

[12] S. Iijima and T. Ichihashi, "Single-shell carbon nanotubes of 1nm diameter," Nature, vol. 363, no. 6430, pp. 603-605, 1993.

[13] V. N. Popov, "Carbon nanotubes: properties and application," Materials Science and Engineering R, vol. 43, no. 3, pp. 61-102, 2004.

[14] A. M. K. Esawi, K. Morsi, A. Sayed, M. Taher, and S. Lanka, "Effect of carbon nanotube (CNT) content on the mechanical properties of CNT-reinforced aluminium composites," Composites Science and Technology, vol. 70, no. 16, pp. 2237-2241, 2010.

[15] R. Pérez-Bustamante, F. Pérez-Bustamante, I. Estrada-Guel et al., "Characterization of $\mathrm{Al}_{2024}$-CNTs composites produced by mechanical alloying," Powder Technology, vol. 212, no. 3, pp. 390-396, 2011.

[16] C. He, N. Zhao, C. Shi et al., "An approach to obtaining homogeneously dispersed carbon nanotubes in Al powders for preparing reinforced Al-matrix composites," Advanced Materials, vol. 19, no. 8, pp. 1128-1132, 2007.

[17] M. S. Senthil Saravanan, K. Sivaprasad, and S. P. Kumaresh Babu, "Dispersion and thermal analysis of Carbon nanotube reinforced AA 4032 Alloy produced by high energy ball milling," Experimental Techniques, vol. 37, no. 4, pp. 14-18, 2013.

[18] H. Ahamed and V. Senthilkumar, "Role of nano-size reinforcement and milling on the synthesis of nano-crystalline aluminium alloy composites by mechanical alloying," Journal of Alloys and Compounds, vol. 505, no. 2, pp. 772-782, 2010.

[19] A. Esawi and K. Morsi, "Dispersion of carbon nanotubes (CNTs) in aluminum powder," Composites $A$, vol. 38, no. 2, pp. 646-650, 2007.

[20] J. Liao and M.-J. Tan, "Mixing of carbon nanotubes (CNTs) and aluminum powder for powder metallurgy use," Powder Technology, vol. 208, no. 1, pp. 42-48, 2011.

[21] A. M. K. Esawi, K. Morsi, A. Sayed, M. Taher, and S. Lanka, “The influence of carbon nanotube (CNT) morphology and diameter on the processing and properties of CNT-reinforced aluminium composites," Composites A, vol. 42, no. 3, pp. 234-243, 2011.

[22] G. S. Upadhyaya, "Some issues in sintering science and technology," Materials Chemistry and Physics, vol. 67, no. 1-3, pp. 1-5, 2001.

[23] C. D. Turner and M. F. Ashby, "The cold isostatic pressing of composite powders-I. Experimental investigations using model powders," Acta Materialia, vol. 44, no. 11, pp. 4521-4530, 1996.

[24] R. M. Govindarajan and N. Aravas, "Deformation processing of metal powders: part I-Cold isostatic pressing," International Journal of Mechanical Sciences, vol. 36, no. 4, pp. 343-357, 1994.

[25] C. Musa, R. Licheri, A. M. Locci et al., "Energy efficiency during conventional and novel sintering processes: the case of Ti$\mathrm{Al}_{2} \mathrm{O}_{3}$-TiC composites," Journal of Cleaner Production, vol. 17, no. 9, pp. 877-882, 2009.

[26] J. Paras, D. Kapoor, C. Haines et al., "Effect of powder processing on Aluminum Carbon nanotube composite consolidation," in Nanotube Reinforced Metal Matrix Composites II: Processing of Nanotube Reinforced MMCs I, Houston, Tex, USA, 2010.

[27] C. Suryanarayana and N. Al-Aqeeli, "Mechanically Alloyed nanocomposites," Progress in Materials Science, vol. 58, no. 4, pp. 383-502, 2013.
[28] C. Deng, X. Zhang, Y. Ma, and D. Wang, "Fabrication of aluminum matrix composite reinforced with carbon nanotubes," Rare Metals, vol. 26, no. 5, pp. 450-455, 2007.

[29] M. Oghbaei and O. Mirzaee, "Microwave versus conventional sintering: a review of fundamentals, advantages and applications," Journal of Alloys and Compounds, vol. 494, no. 1-2, pp. 175-189, 2010.

[30] H. Kwon and A. Kawasaki, "Extrusion of spark plasma sintered aluminum-carbon nanotube composites at various sintering temperatures," Journal of Nanoscience and Nanotechnology, vol. 9, no. 11, pp. 6542-6548, 2009.

[31] J. K. Rana, D. Sivaprahasam, K. Seetharama Raju, and V. Subramanya Sarma, "Microstructure and mechanical properties of nanocrystalline high strength Al-Mg-Si (AA6061) alloy by high energy ball milling and spark plasma sintering," Materials Science and Engineering A, vol. 527, no. 1-2, pp. 292-296, 2009.

[32] H. Kwon, M. Estili, K. Takagi, T. Miyazaki, and A. Kawasaki, "Combination of hot extrusion and spark plasma sintering for producing carbon nanotube reinforced aluminum matrix composites," Carbon, vol. 47, no. 3, pp. 570-577, 2009.

[33] N. Saheb, A. Khalil AS Hakeem, N. Al-Aqeeli, and T. Laoui AK Al-Qutub, "Spark plasma sintering of CNT reinforced Al6061 and Al2124 nanocomposites," submitted to. Journal of Composite Materials.

[34] N. Saheb, "Spark plasma and microwave sintering of Al6061 and Al2124 alloys," International Journal of Minerals, Metallurgy and Materials, vol. 20, no. 2, pp. 152-159, 2013. 

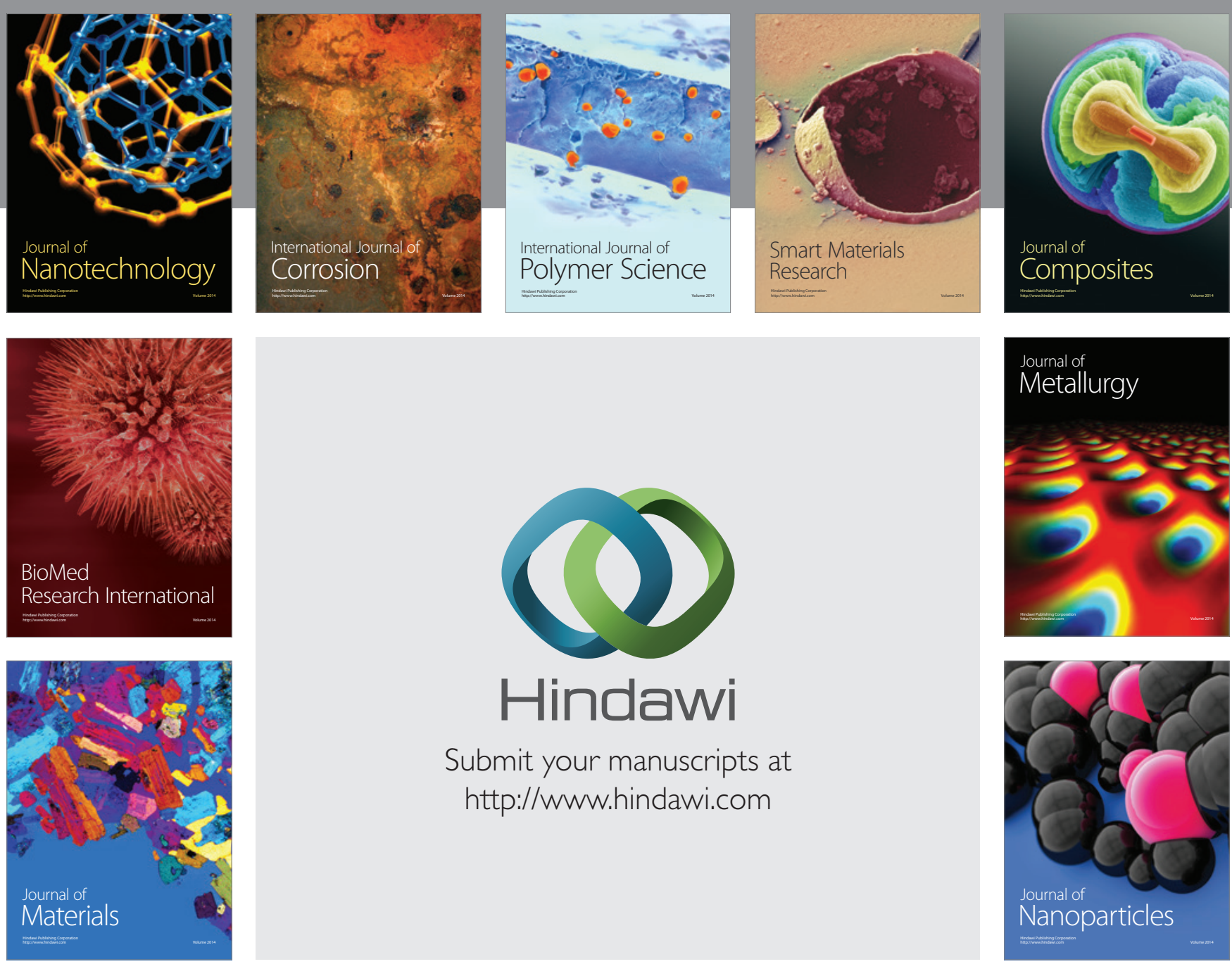

Submit your manuscripts at http://www.hindawi.com
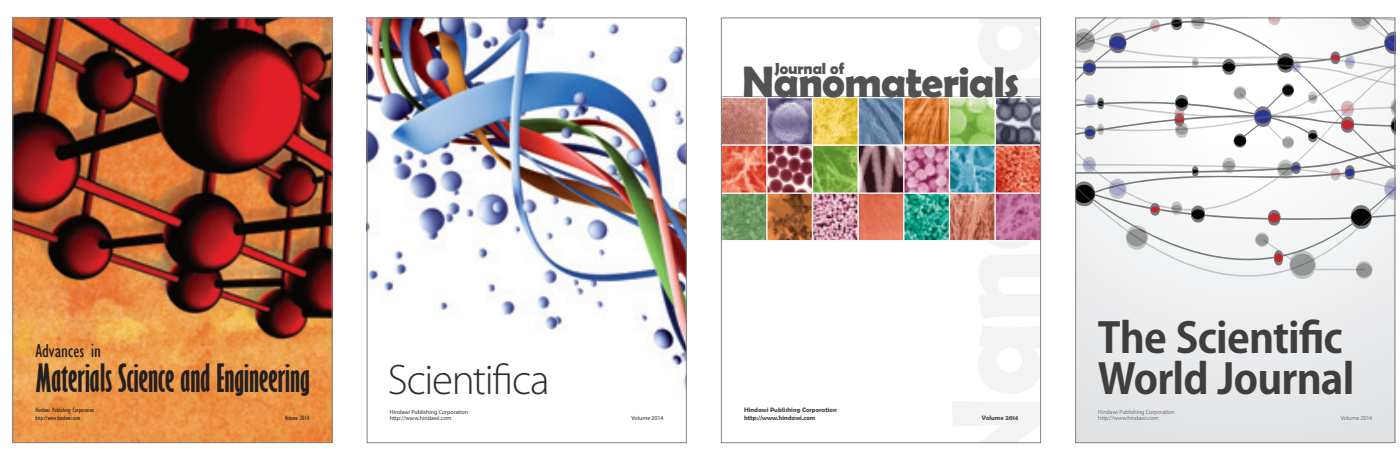

\section{The Scientific World Journal}
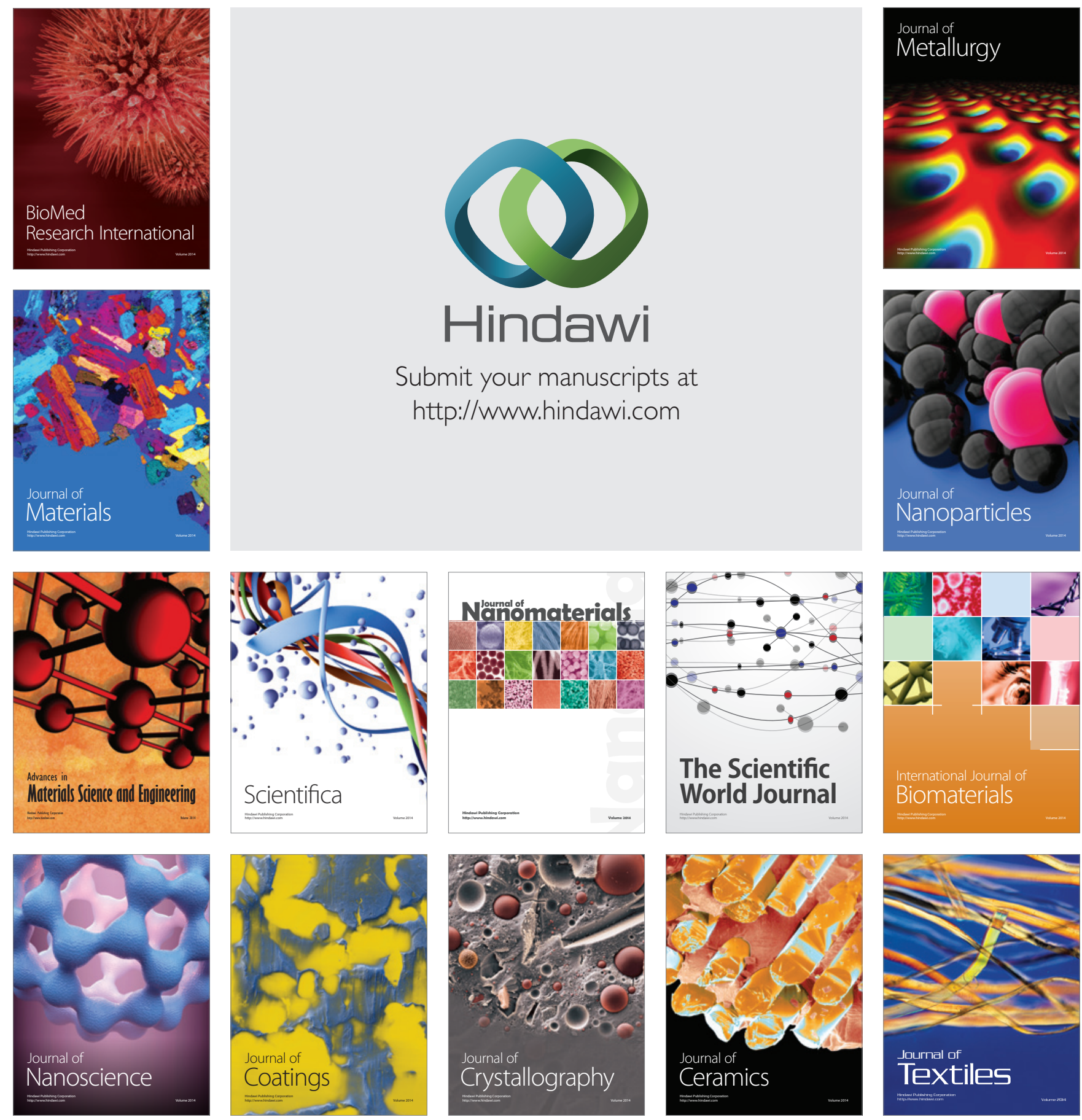